\title{
Multiobjective Genetic Algorithm Optimization Of The Composite Laminates As A Satellite Structure Material For Coefficient Of Thermal Expansion And Elastic Modulus
}

\author{
Levent Aydin \\ Mechanical Engineering \\ Izmir Institute of Technology \\ Izmir, Turkey \\ leventaydin@iyte.edu.tr
}

\author{
H.Secil Artem \\ Mechanical Engineering \\ Izmir Institute of Technology \\ Izmir, Turkey \\ secilartem@iyte.edu.tr
}

\begin{abstract}
This study considers multi-objective optimal design of the fiber reinforced symmetric-balanced laminated composites using genetic algorithms. MATLAB Genetic Algorithm and Direct Search Toolbox is used to obtain Pareto-optimal design for three different model problems. The objectives of the problems are to maximize the Young's moduli and minimize the coefficient of thermal expansion (CTE) simultaneously for 8 and 16 layered carbon/epoxy composites. Simplified micromechanics equations and classical lamination theory are used in order to obtain the fitness functions of the problems. Stress and strain distributions are presented through the thickness of the laminates for the optimized problems under mechanical and thermal loadings.
\end{abstract}

Keywords-multi-objective optimization; genetic algortihms; satellite structures; laminated composites; thermomechanical loading

\section{INTRODUCTION}

This study considers multi-objective optimal design of fiber reinforced composites widely used in aerospace engineering applications. Space structure materials should exhibit the features low density, high stiffness, low coefficients of thermal and moisture expansions. Carbon fiber reinforced polymer composite materials can match these requirements with an appropriate stacking sequence. Multi-objective optimization of laminated composite materials have been studied by several authors in literature. The problem of the multi-objective optimal design of laminated composite structures has been studied by [1], incorporating the applicable criteria that follow. A methodology for the multi-objective optimization of laminated composite materials that is based on an integercoded genetic algorithm has presented by [2]. The fiber orientations and fiber volume fractions of the lamina are chosen as the primary optimization variables. Simplified micromechanics equations are used to estimate the stiffness and strength of each lamina using the fiber volume fraction and material properties of the matrix and fibers. Design and control optimization is presented to minimize the thermal post buckling dynamic response and to maximize the buckling temperature level of composite laminated plates subjected to thermal distribution varying linearly through the thickness and arbitrarily with respect to the in-plane coordinates [3]. The thickness of layers and the fibers orientation angles are taken as optimization design variables. The design and control objectives are formulated based on shear deformation theory accounting for the von-Karman nonlinearity. Reference [4] studied two examples of multi-objective optimization of composite laminate plates using GA and FEM. Minimization of two objectives, such as weight and deflection or weight and cost, are simultaneously performed and a pareto-optimal set is obtained by shifting the optimization emphasis using a weighting factor.

The aim of the present study is to design stacking sequence in order to minimize the CTE while maximizing stiffness of the composite. In-plane design of eight-layered $\left( \pm \theta_{1} / \pm \theta_{2}\right)_{\mathrm{s}}$ and sixteen-layered $\left( \pm \theta_{1} / \pm \theta_{2} / \pm \theta_{3} / \pm \theta_{4}\right)_{\mathrm{s}}$ symmetric-balanced laminated plates are considered. This work consists of three main parts:

In the first part, simplified micromechanics expressions are used to predict the stiffness and thermal expansion coefficients of a lamina using constituent material properties. The classical lamination theory is utilized to determine the effective elastic modulus and the effective thermal expansion coefficients for composite laminates.

The effective elastic properties obtained from the first part of the study defining the fitness functions have been used to obtain the optimum fiber orientation angles of each layer by a stochastic search technique called genetic algorithms (GAs). MATLAB Genetic Algorithm and Direct Search Toolbox is 
used to obtain Pareto-optimal design [5] for three different model problems considered.

In the last part, stresses and strains have been calculated for each layer of the optimized composite subjected to the thermal and mechanical loadings.

\section{FORMULATION}

\section{A. Macro-Mechanical Analysis}

The infinitesimal deformation of thin laminate is analyzed using classical lamination theory. The force and moment resultants on a laminate are related to the mid-plane strains $\varepsilon_{\mathrm{x}}^{0}$, $\varepsilon_{\mathrm{y}}^{0}, \gamma_{\mathrm{xy}}^{0}$ and curvatures $\kappa_{\mathrm{x}}, \kappa_{\mathrm{y}}, \kappa_{\mathrm{xy}}$ as

$$
\left[\begin{array}{l}
\mathrm{N}_{\mathrm{x}} \\
\mathrm{N}_{\mathrm{y}} \\
\mathrm{N}_{\mathrm{xy}}
\end{array}\right]=\left[\begin{array}{lll}
\mathrm{A}_{11} & \mathrm{~A}_{12} & \mathrm{~A}_{16} \\
\mathrm{~A}_{12} & \mathrm{~A}_{22} & \mathrm{~A}_{26} \\
\mathrm{~A}_{16} & \mathrm{~A}_{26} & \mathrm{~A}_{66}
\end{array}\right]\left[\begin{array}{c}
\varepsilon_{\mathrm{x}}^{\circ} \\
\varepsilon_{\mathrm{y}}^{\circ} \\
\gamma_{\mathrm{xy}}^{\circ}
\end{array}\right]+\left[\begin{array}{ccc}
\mathrm{B}_{11} & \mathrm{~B}_{12} & \mathrm{~B}_{16} \\
\mathrm{~B}_{12} & \mathrm{~B}_{22} & \mathrm{~B}_{26} \\
\mathrm{~B}_{16} & \mathrm{~B}_{26} & \mathrm{~B}_{66}
\end{array}\right]\left[\begin{array}{c}
\kappa_{\mathrm{x}} \\
\kappa_{\mathrm{y}} \\
\kappa_{\mathrm{xy}}
\end{array}\right]
$$

where matrices [A], [B] and [D] are the extensional stiffness, the bending stiffness and the bending-extensional stiffness, respectively. When comparing the stiffness of different laminates, especially symmetric laminates that are subjected to in-plane loading, it is often convenient to define the effective extensional moduli $\mathrm{E}_{\mathrm{x}}$ and $\mathrm{E}_{\mathrm{y}}$ [6]. For $\mathrm{a}$ symmetric laminate, [B] becomes zero and then (1) takes the form of

$$
\left[\begin{array}{c}
\varepsilon_{\mathrm{x}}^{0} \\
\varepsilon_{\mathrm{y}}^{0} \\
\gamma_{\mathrm{xy}}^{0}
\end{array}\right]=\left[\begin{array}{ccc}
\mathrm{A}_{11}^{*} & \mathrm{~A}_{12}^{*} & \mathrm{~A}_{16}^{*} \\
\mathrm{~A}_{12}^{*} & \mathrm{~A}_{22}^{*} & \mathrm{~A}_{26}^{*} \\
\mathrm{~A}_{16}^{*} & \mathrm{~A}_{26}^{*} & \mathrm{~A}_{66}^{*}
\end{array}\right]\left[\begin{array}{l}
\mathrm{N}_{\mathrm{x}} \\
\mathrm{N}_{\mathrm{y}} \\
\mathrm{N}_{\mathrm{xy}}
\end{array}\right]
$$

where $\left[\mathrm{A}^{*}\right]=[\mathrm{A}]^{-1}$.

For the purpose of multi-objective optimization of laminate, coefficients of thermal expansion are defined as

$$
\left[\begin{array}{c}
\alpha_{\mathrm{x}} \\
\alpha_{\mathrm{y}} \\
\alpha_{\mathrm{xy}}
\end{array}\right]=\left[\begin{array}{c}
\varepsilon_{\mathrm{x}}^{0} \\
\varepsilon_{\mathrm{y}}^{0} \\
\gamma_{\mathrm{xy}}^{0}
\end{array}\right]_{\Delta \mathrm{T}=0}=\left[\begin{array}{ccc}
\mathrm{A}_{11}^{*} & \mathrm{~A}_{12}^{*} & \mathrm{~A}_{16}^{*} \\
\mathrm{~A}_{12}^{*} & \mathrm{~A}_{22}^{*} & \mathrm{~A}_{26}^{*} \\
\mathrm{~A}_{16}^{*} & \mathrm{~A}_{26}^{*} & \mathrm{~A}_{66}^{*}
\end{array}\right]\left[\begin{array}{c}
\mathrm{N}_{\mathrm{x}}^{\mathrm{T}} \\
\mathrm{N}_{\mathrm{y}}^{\mathrm{T}} \\
\mathrm{N}_{\mathrm{xy}}^{\mathrm{T}}
\end{array}\right]
$$

where

$$
\left[\mathrm{N}^{\mathrm{T}}\right]=\left[\begin{array}{c}
\mathrm{N}_{\mathrm{x}}^{\mathrm{T}} \\
\mathrm{N}_{\mathrm{y}}^{\mathrm{T}} \\
\mathrm{N}_{\mathrm{xy}}^{\mathrm{T}}
\end{array}\right]=\Delta \mathrm{T} \sum_{\mathrm{k}=1}^{\mathrm{n}}\left[\begin{array}{lll}
\overline{\mathrm{Q}}_{11} & \overline{\mathrm{Q}}_{12} & \overline{\mathrm{Q}}_{16} \\
\overline{\mathrm{Q}}_{12} & \overline{\mathrm{Q}}_{22} & \overline{\mathrm{Q}}_{26} \\
\overline{\mathrm{Q}}_{16} & \overline{\mathrm{Q}}_{26} & \overline{\mathrm{Q}}_{66}
\end{array}\right]_{\mathrm{k}}\left[\begin{array}{c}
\alpha_{\mathrm{x}} \\
\alpha_{\mathrm{y}} \\
\alpha_{\mathrm{xy}}
\end{array}\right]_{\mathrm{k}}\left(\mathrm{h}_{\mathrm{k}}-\mathrm{h}_{\mathrm{k}-1}\right)
$$

$\left[\mathrm{N}^{\mathrm{T}}\right]$ given in (4) is the resultant thermal force corresponding to $\Delta \mathrm{T}=1, \Delta \mathrm{C}=0$. Here, $\overline{\mathrm{Q}}_{\mathrm{ij}}$ are the elements of the transformed reduced stiffness matrix, $h_{k}$ represents the distance of the lamina measured from the mid-plane of composite plate.

\section{B. Micro-Mechanical Analysis}

Micromechanical expressions used to predict the stiffness and thermal expansion coefficients of a lamina using constituent material properties are given as $[7,8]$

$$
\begin{gathered}
E_{1}=V_{f} E_{1 f}+\left(1-V_{f}\right) E_{m} \\
E_{2}=\frac{E_{m}}{1-\sqrt{V_{f}}\left(1-E_{m} / E_{2 f}\right)} \\
G_{12}=\frac{G_{m}}{1-\sqrt{V_{f}}\left(1-G_{m} / G_{12 f}\right)} \\
v_{12}=V_{f} v_{12 f}+\left(1-V_{f}\right) v_{m} \\
\alpha_{1}=\frac{V_{f} \alpha_{1 f} E_{1 f}+\left(1-V_{f}\right) \alpha_{m} E_{m}}{E_{1}} \\
\alpha_{2}=\alpha_{2 f} \sqrt{V_{f}}+\left(1-\sqrt{V_{f}}\right)\left(1-V_{f} v_{m} E_{1 f} / E_{1}\right) \alpha_{m}
\end{gathered}
$$

where indices 1 and 2 , $\mathrm{f}$ and $\mathrm{m}$ appearing above equations denote the longitudinal and transverse directions, fiber and matrix properties, respectively. $V_{f}$ represents the fiber volume fraction of the lamina.

\section{Genetic Algorithm}

Many engineering design problems are very complex and nonsolvable by the traditional optimization techniques. The genetic algorithm (GA) is a numerical optimization and search technique which allows to obtain alternative solutions some of this complex engineering problems. GA method based on the principles of genetics and natural selection. This method is simple to understand and uses three simple operators, selection, crossover and mutation. In multi-objective optimization problems, multiple objective functions need to be optimized simultaneously. There exist a set of solutions for the multiple objective case and such solutions called non-dominated solutions or Pareto optimal solutions. There is not a solution that is best with respect to all objectives in multi-objective optimization. One solution can be better in one objective while worse in another [9]. To find a set of solutions as diverse as possible and as close as possible to Pareto front are very important [10].

\section{MODEL PROBLEMS}

Three model problems studied in our work. The first two problems consider eight-layered $\left( \pm \theta_{1} / \pm \theta_{2}\right)_{\mathrm{s}}$ symmetric and balanced continuous carbon fiber reinforced epoxy matrix composite plates design and optimization. Design variables are the fiber orientation angles $\theta_{1}$ and $\theta_{2}$. Similarly, in the third problem sixteen-layered $\left( \pm \theta_{1} / \pm \theta_{2} / \pm \theta_{3} / \pm \theta_{4}\right)_{\mathrm{s}}$ plates are studied for design variables $\theta_{1}, \theta_{2}, \theta_{3}$ and $\theta_{4}$. In all model problems, the fiber volume fraction is taken as 0.50 and thickness of each layer is $150.10^{-6} \mathrm{~m}$. Laminates are subjected to loadings [7] $\mathrm{F}_{\mathrm{x}}=20 \mathrm{kN}, \mathrm{F}_{\mathrm{y}}=20 \mathrm{kN}, \mathrm{F}_{\mathrm{xy}}=0 \mathrm{kN}$ with 
plate width $=0.3 \mathrm{~m}$ and temperature change is $\Delta \mathrm{T}=-150^{\circ} \mathrm{C}$ leads to thermal loads.

Objective of the first problem is to maximize Young's modulus $\mathrm{E}_{\mathrm{x}}$ and minimize the coefficient of thermal expansion $\alpha_{\mathrm{x}}$ of the composite, simultaneously. The goal for the second problem is to maximize Young's moduli $\mathrm{E}_{\mathrm{x}}$ and $\mathrm{E}_{\mathrm{y}}$ while minimizing the coefficient of thermal expansion $\alpha_{\mathrm{x}}$. Lastly, in the third problem Young's modulus $\mathrm{E}_{\mathrm{x}}$ is maximized while minimizing the coefficient of thermal expansion $\alpha_{\mathrm{x}}$ for sixteen-layered plates.

\section{MATLAB GAMULTIOBJ SOLVER OPTIONS FOR PROBLEMS}

MATLAB gamultiobj solver works on a population using a set of operators that are applied to the population [11]. A population is a set of points in the design space. The initial population is generated randomly by default. The next generation of the population is computed using the nondominated rank and a distance measure of the individuals in the current generation. A non-dominated rank is assigned to each individual using the relative fitness. This optimization tool options include following nine fundamental processes:

\section{1)Population 2)Selection 3)Reproduction 4)Mutation} 5)Crossover 6)Migration 7)Multi-objective problem settings 8)Hybrid function 9)Stopping criteria

Population size is $15 *$ number of design variables as a default value, however one can specify the population size as any integer depending on the problem. Initial population, initial scores and initial range can also be identified in the vectored form.

In the present study, our selections are double vector for population type. Population sizes are set as 40 and 60 for the first two (eight-layered) and the third(sixteen-layered) model problems, respectively . Initial range which defines bounds of fiber orientation angels are [-90 -90; 90 90] (This implies that bounds for the problems are $-90 \leq \theta_{1} \leq 90$ and $-90 \leq \theta_{2} \leq 90$ ) for problems1 and 2; and [-90 -90 -90 -90; 90 9090 90] for problem 3 in the vectored form. In addition to this, constraint dependent creation function is utilized as a suboption in the Population part. Selection option uses Tournament selection function. The selection function chooses parents for the next generation based on their scaled values from the fitness functions. An ideal selection strategy should be such that it is able to adjust its selective pressure and population diversity so as to fine-tune GA search performance. Reproduction options determine how the genetic algorithm creates children at each new generation. In the toolbox Crossover fraction is used as a sub-option. This property specifies the fraction of the next generation that crossover produces. Mutation produces the remaining individuals in the next generation. Crossover fraction must be a fraction between 0 and 1. The value 0.8 (default) is selected for problems. Mutation option has four different mutation functions such as Constraint dependent, Gaussian, Uniform and Adaptive feasible. If there are no constraints or bounds in the specified problem Gaussian can be selected, otherwise Adaptive feasible sub-option should be used. Because of the bounds for our problems, Adaptive feasible mutation option is to be used. In the Crossover option, it should be specified the function that performs the crossover in the sub-option Crossover function. There exist following six different crossover functions in the toolbox: Scattered, Single point, Two point, Intermediate, Heuristic and Arithmetic. Intermediate function with 1.0 Ratio is selected as a Crossover function. Our Migration selections for the model problems are Direction $=>$ both, Fraction $=>0.2$, Interval $=>20$.

Table1 shows some selected Pareto-optimal design results with corresponding coefficients of moisture expansions for biobjective optimization of problem1. If the fiber orientation angles are selected $0^{\circ}$ for all lamina as expected the Young's modulus on $\mathrm{x}$ direction is maximum $\left(\mathrm{E}_{\mathrm{x}}(\max )=277.3 \mathrm{GPa}\right)$. However, this design is not suitable for minimum coefficient of thermal expansion $\left(\alpha_{\mathrm{x}}=-1.0\left(10^{-6} /{ }^{\circ} \mathrm{C}\right)\right)$. Similarly, if all of the fiber orientation angles are selected as $32^{\circ}$, the CTE becomes minimum $\left(\alpha_{\mathrm{x}}(\min )=-5.24\left(10^{-6} /{ }^{\circ} \mathrm{C}\right)\right)$ but this is not an appropriate design for Young's modulus of the composite $\left(\mathrm{E}_{\mathrm{x}}=40.8 \mathrm{GPa}\right)$. More reliable solutions are given in Table 1 as designs 1 to 9 . From the viewpoint of practical engineering usage, only one of these solutions is to be chosen. For example, considering designs 4 and 6 the Young's modulus of 4 is $12.8 \%$ smaller than that of design 6 while CTE of 6 is $\% 14.5$ larger than that of 4 . One solution (design 4) can be selected which satisfied by the constraints $\mathrm{E}_{\mathrm{x}}>165 \mathrm{GPa}$ and $\alpha_{\mathrm{x}}<-2.80 .10^{-6} /{ }^{\circ} \mathrm{C}$ and the stacking sequences become $[ \pm 14.9 / \mp 20.5]_{S}$. 14 selected Pareto-optimal solution for problem 2 are given in Table 2 . In this problem, design 8 is chosen with the constraint assumptions $\mathrm{E}_{\mathrm{x}}>180 \mathrm{GPa}, \mathrm{E}_{\mathrm{y}}>9.5$ $\mathrm{GPa}$ and $\alpha_{\mathrm{x}}<-2.30 \cdot 10^{-6} /{ }^{\circ} \mathrm{C}$. Therefore, the corresponding stacking sequence for the 8 layered composite becomes $[ \pm 5.7 / \pm 25.5]_{\mathrm{S}}$. In the last model problem (problem3), 9 new selected Pareto-optimal solution can be obtained for 16 layered composite plate. Assuming the constraints for problem 3 as $\mathrm{E}_{\mathrm{x}}>170 \mathrm{GPa}$ and $\alpha_{\mathrm{x}}<-2.80 .10^{-6} /{ }^{\circ} \mathrm{C}$, design 6 becomes an appropriate solution among the other candidate solutions. Therefore, the stacking sequence is to be $[ \pm 13.1 / \pm 14.9 / \pm 21.6 / \pm 20.2]_{S}$.

Investigation of stresses and strains for the optimized problems under mechanical and thermal loadings give some additional information about composite design and this provides production of safer structures [12]. Lamination stresses and strains can be analyzed by using lamination theory and micromechanical equations. Experimentally, they can be determined using embedded strain gage techniques. Figures 13 show the normal and shear stresses distributions through the thickness of the laminated composites for the model problems 1-3, respectively. The corresponding strain components are given in Table 4. 
TABLE I. SELECTED PARETO OPTIMAL SOLUTIONS FOR BIOBJECTIVE OPTIMIZATION (PROBLEM1) OF A COMPOSITE PLATE FOR MAXIMUM YOUNG'S MODULUS AND MINIMUM COEFFICIENT OF THERMAL EXPANSION WITH CORRESPONDING COEFFICIENT OF MOISTURE EXPANSION

\begin{tabular}{|c|c|c|c|c|c|}
\hline Design & $\begin{array}{c}\mathrm{E}_{\mathrm{x}} \\
(\mathrm{GPa})\end{array}$ & $\begin{array}{c}\alpha_{\mathrm{x}} \\
\left(10^{-6} /{ }^{\mathrm{C}}\right)\end{array}$ & $\begin{array}{c}\beta_{\mathrm{x}} \\
\left(10^{-6} / \% \mathrm{M}\right)\end{array}$ & $\begin{array}{c}\theta_{1} \\
(\mathrm{deg})\end{array}$ & $\begin{array}{c}\theta_{2} \\
(\mathrm{deg})\end{array}$ \\
\hline $\mathbf{1}$ & 115.9 & -3.66 & -58.8 & 25.9 & -19 \\
\hline $\mathbf{2}$ & 127.6 & -3.49 & -54.1 & 24.6 & -18 \\
\hline $\mathbf{3}$ & 152.7 & -3.21 & -46.1 & 20 & -18 \\
\hline $\mathbf{4}$ & 169.4 & -2.89 & -37.3 & 14.9 & -20.5 \\
\hline $\mathbf{5}$ & 188 & -2.63 & -29.9 & 13.8 & -18.5 \\
\hline $\mathbf{6}$ & 194.2 & -2.44 & -24.7 & 20.6 & -10.2 \\
\hline $\mathbf{7}$ & 206.9 & -2.16 & -17.0 & 4.7 & -21.6 \\
\hline $\mathbf{8}$ & 222.1 & -1.99 & -12.2 & 19.5 & -2.6 \\
\hline $\mathbf{9}$ & 239.9 & -1.80 & -6.8 & 8.1 & -13.7 \\
\hline
\end{tabular}

TABLE II. SELECTED PARETO OPTIMAL SOLUTIONS FOR MULTIOBJECTIVE OPTIMIZATION (PROBLEM2) OF A COMPOSITE PLATE FOR MAXIMUM YOUNG'S MODULI AND MINIMUM COEFFICIENT OF THERMAL EXPANSION WITH CORRESPONDING COEFFICIENT OF MOISTURE EXPANSION

\begin{tabular}{|c|c|c|c|c|c|c|}
\hline Design & $\begin{array}{c}\mathrm{E}_{\mathrm{x}} \\
(\mathrm{GPa})\end{array}$ & $\begin{array}{c}\mathrm{E}_{\mathrm{y}} \\
(\mathrm{GPa})\end{array}$ & $\begin{array}{c}\alpha_{\mathrm{x}} \\
\left(10^{-6} /{ }^{\circ} \mathrm{C}\right)\end{array}$ & $\begin{array}{c}\beta_{\mathrm{x}} \\
\left(10^{-6} / \% \mathrm{M}\right)\end{array}$ & $\begin{array}{c}\theta_{1} \\
(\mathrm{deg})\end{array}$ & $\begin{array}{c}\theta_{2} \\
(\mathrm{deg})\end{array}$ \\
\hline $\mathbf{1}$ & 149,5 & 9,1 & $-2,90$ & $-36,3$ & 13 & 26,5 \\
\hline $\mathbf{2}$ & 159,5 & 16,9 & $-1,90$ & $-9,7$ & 1,2 & 34,7 \\
\hline $\mathbf{3}$ & 159,8 & 13,0 & $-2,21$ & $-18,3$ & 6,5 & 31,2 \\
\hline $\mathbf{4}$ & 161,3 & 7,4 & $-3,00$ & $-40,5$ & 15,5 & 21,2 \\
\hline $\mathbf{5}$ & 170,2 & 8,4 & $-2,69$ & $-31,8$ & 11,6 & 23,7 \\
\hline $\mathbf{6}$ & 172,4 & 11,8 & $-2,20$ & $-17,9$ & 3,9 & 29,2 \\
\hline $\mathbf{7}$ & 181,9 & 8,0 & $-2,57$ & $-28,4$ & 10,9 & 22,1 \\
\hline $\mathbf{8}$ & 184,1 & 9,7 & $-2,31$ & $-21,0$ & 5,7 & 25,5 \\
\hline $\mathbf{9}$ & 190,2 & 7,2 & $-2,60$ & $-29,2$ & 13,7 & 18,3 \\
\hline $\mathbf{1 0}$ & 193,2 & 8,5 & $-2,34$ & $-21,8$ & 7,4 & 22,7 \\
\hline $\mathbf{1 1}$ & 202,6 & 9,0 & $-2,15$ & $-16,5$ & 1,2 & 23,3 \\
\hline $\mathbf{1 2}$ & 217,8 & 8,1 & $-2,04$ & $-13,4$ & 2,5 & 20,3 \\
\hline $\mathbf{1 3}$ & 234,0 & 7,6 & $-1,85$ & $-8,1$ & 2,1 & 17,4 \\
\hline $\mathbf{1 4}$ & 245,9 & 7,4 & $-1,67$ & $-3,3$ & 0,3 & 15,2 \\
\hline & & & & & & \\
\hline
\end{tabular}

It can be observed from Fig.1, maximum normal stresses occur in ply numbers 3-6 and shear stress in 4, 5 when the composite subjected to mechanical load. Applying only thermal load, relatively lower stresses are obtained for both normal and shear stresses. Combination of thermal and mechanical loading leads to decrease the effect of mechanical load and therefore, this produces lower values of normal and shear stresses.

Considering Fig.2, it can be seen that relatively higher values of maximum normal and shear stresses are obtained. Ply numbers thorough 3-6 for normal stresses, 3 and 6 for shear stress produce maximum stresses after only mechanical load applied. More complicated stress distribution for shear stress compared to normal stresses is also observed from Fig.2.
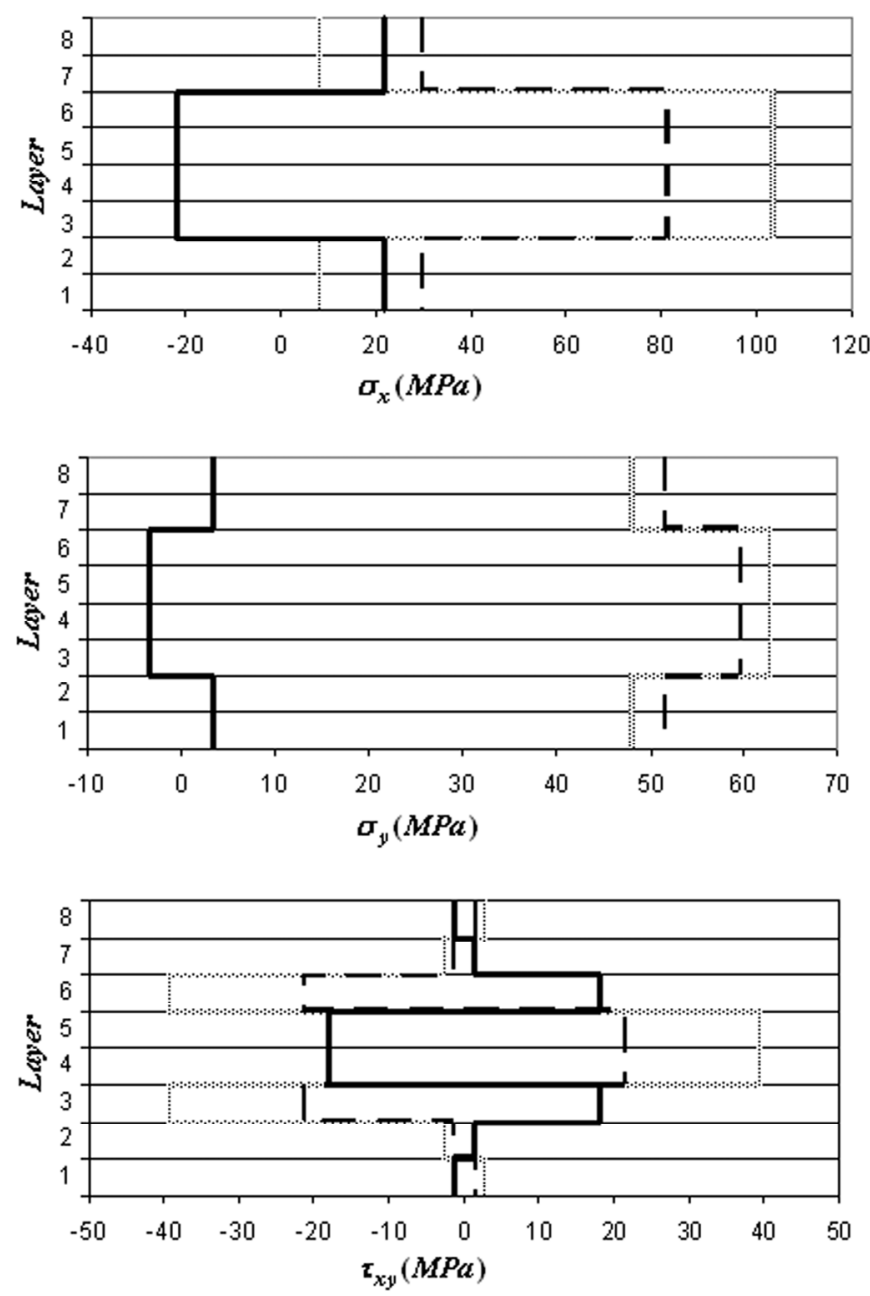

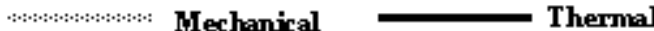

Mechanical+T hermal

Figure 1. Stresses distribution of the composite subjected to combination of mechanical and thermal loads for model problem1.

It should be noted that for problem3 only lower half part of the laminate are given in Fig.3 due to symmetry. A smooth normal and shear stresses variations for combination of mechanical and thermal loads are observed. Similar to the previous problems, mechanical load dominates to thermal load.

\section{CONCLUSION}

A multi-objective optimal design of the fiber reinforced symmetric-balanced laminated composite problem is presented. The fiber orientation angels are chosen as design variables. MATLAB Genetic Algorithm and Direct Search Toolbox based on a recent multi-objective optimization algorithm NSGA-II is used to obtain the Pareto-optimal designs for the model problems. In order to obtain the fitness functions for the multi-objective optimization process, classical lamination 
TABLE III. SELECTED PARETO OPTIMAL SOLUTIONS FOR MULTIOBJECTIVE OPTIMIZATION (PROBLEM3) OF A COMPOSITE PLATE FOR MAXIMUM YOUNG'S MODULI AND MINIMUM COEFFICIENT OF THERMAL EXPANSION WITH CORRESPONDING COEFFICIENT OF MOISTURE EXPANSION

\begin{tabular}{|c|c|c|c|c|c|c|c|}
\hline Design & $\begin{array}{c}\mathbf{E}_{\mathbf{x}} \\
(\mathbf{G P a})\end{array}$ & $\begin{array}{c}\boldsymbol{\alpha}_{\mathbf{x}} \\
\left(\mathbf{1 0} \mathbf{6}^{\mathbf{0}} \mathbf{C}\right)\end{array}$ & $\begin{array}{c}\boldsymbol{\beta}_{\mathbf{x}} \\
(\mathbf{1 0}-\mathbf{6} / \mathbf{M M})\end{array}$ & $\begin{array}{c}\boldsymbol{\theta}_{\mathbf{1}} \\
(\mathbf{d e g})\end{array}$ & $\begin{array}{c}\boldsymbol{\theta}_{\mathbf{2}} \\
(\mathbf{d e g})\end{array}$ & $\begin{array}{c}\boldsymbol{\theta}_{3} \\
(\mathbf{d e g})\end{array}$ & $\begin{array}{c}\boldsymbol{\theta}_{4} \\
(\mathbf{d e g})\end{array}$ \\
\hline 1 & 135.1 & -3.50 & -54.3 & 19.7 & 21.9 & 19.7 & 20.4 \\
\hline 2 & 138.9 & -3.39 & -51.2 & 19.4 & 20.2 & 23.5 & 17.6 \\
\hline 3 & 153.7 & -3.20 & -45.9 & 19.9 & 18.5 & 18 & 19.4 \\
\hline 4 & 162.2 & -3.04 & -41.5 & 17 & 17 & 20.3 & 18.6 \\
\hline 5 & 167.7 & -2.93 & -38.5 & 20.8 & 15.2 & 18.7 & 16.5 \\
\hline 6 & 172.3 & -2.82 & -35.2 & 13.1 & 14.9 & 21.6 & 20.2 \\
\hline 7 & 191.2 & -2.59 & -29.0 & 18 & 14.2 & 16.2 & 15.2 \\
\hline 8 & 198.9 & -2.47 & -25.4 & 18.6 & 13.8 & 13.8 & 14.8 \\
\hline 9 & 226.2 & -2.02 & -13.1 & 10.9 & 12.7 & 17.5 & 9 \\
\hline
\end{tabular}
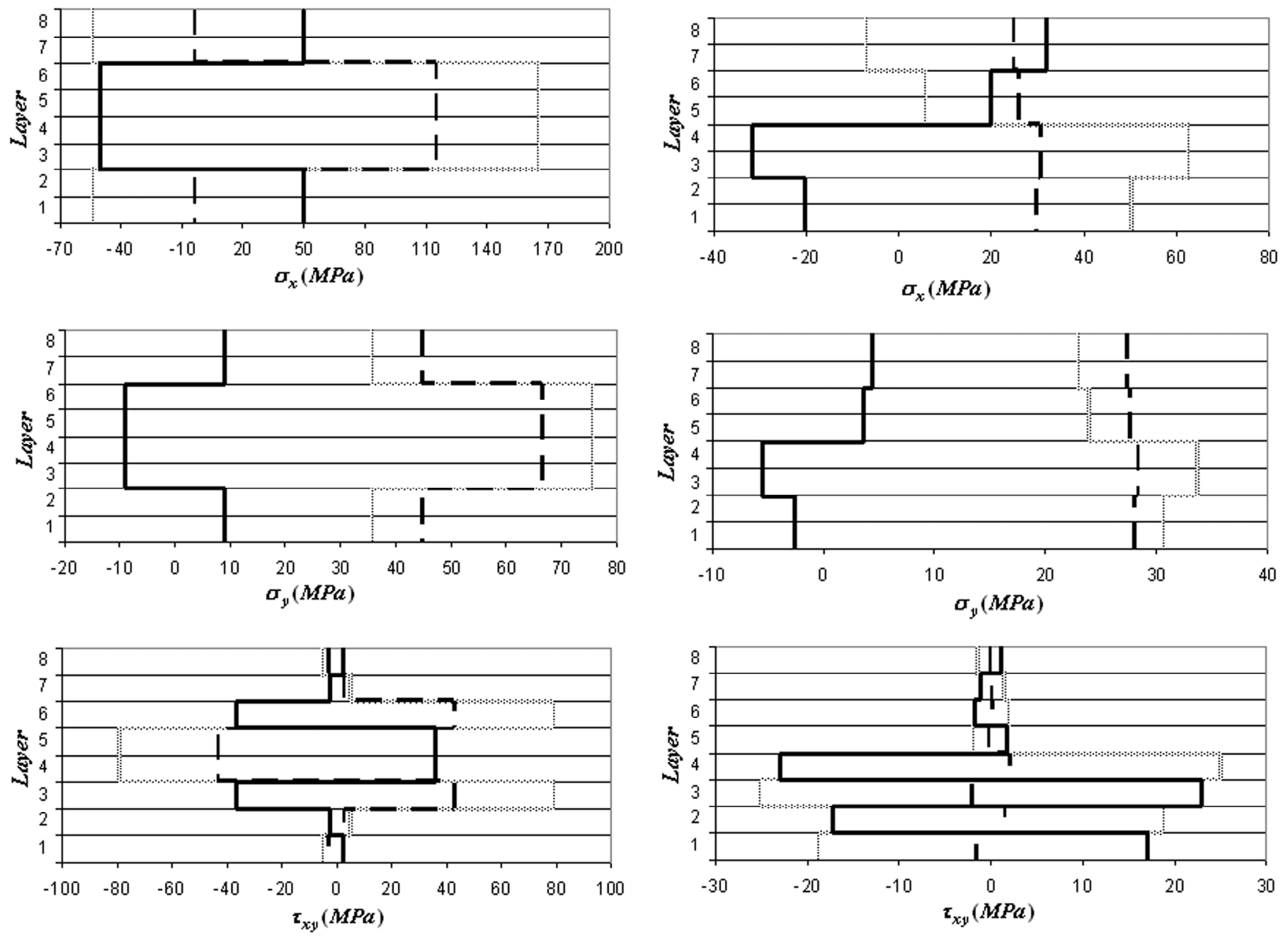

:

Thermal

Hechanicalt Thermal

Figure 2. Stresses distribution of the composite subjected to combination of mechanical and thermal loads for model problem 2 .

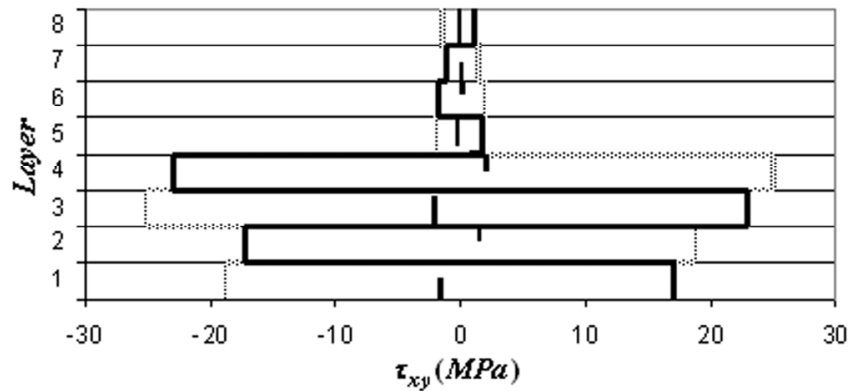

Mechanical

Thermal

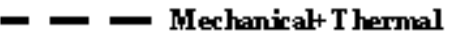

Figure 3. Stresses distribution of lower half part of the composite subjected to mechanical, thermal loads for model problem3. 
TABLE IV. STRAIN COMPONENTS FOR MODEL PROBLEMS

\begin{tabular}{|c|c|c|c|}
\hline \multirow{3}{*}{ Problem } & Loading & $\begin{array}{c}\boldsymbol{\varepsilon}_{\mathrm{x}} \\
\left(10^{-6}\right)\end{array}$ & $\begin{array}{c}\boldsymbol{\varepsilon}_{\mathrm{y}} \\
\left(10^{-6}\right)\end{array}$ \\
\hline \multirow{3}{*}{$\mathbf{1}$} & Mech & -478.1 & 6717.3 \\
\cline { 2 - 4 } & Therm & 433.7 & -2859.4 \\
\cline { 2 - 4 } & Mech+Therm & -44.3 & 3857.9 \\
\hline \multirow{3}{*}{$\mathbf{3}$} & Mech & -286.2 & 5171.6 \\
\cline { 2 - 4 } & Therm & 345.9 & -2152 \\
\cline { 2 - 4 } & Mech+Therm & 60 & 3019.6 \\
\hline \multirow{3}{*}{3} & Mech & -226.6 & 3304 \\
\cline { 2 - 4 } & Therm & 422.3 & -2809.2 \\
\cline { 2 - 4 } & Mech+Therm & 195.7 & 494.6 \\
\hline
\end{tabular}

theory, simplified micro-mechanical equations and MATLAB Symbolic Math Toolbox are utilized. All of the model problems investigated in the present paper consider minimization of CTE and maximization of elastic moduli simultaneously. However, resulting fiber orientation angels automatically minimize the coefficient of moisture expansion (CME) and this gives an important advantage for the materials used in satellite structures. Therefore, it is sufficient to minimize the CTE only and not necessary to solve a new optimization problem in order to minimize the CME of the laminated composites. It is found that mechanical loads dominate to thermal effect in all problems for given loading and environmental conditions. The results demonstrate that model problem3 produce relatively low normal and shear stresses compared to the others. It is also found that maximization of $\mathrm{E}_{\mathrm{x}}$ and minimization of $\alpha_{\mathrm{x}}$ produces lower strain values on $\mathrm{x}$ direction in all model problems.

[1] R. Spallino and S. Rizzo, "Multiobjective discrete optimization of laminated structures", Mech. Res. Commun., vol. 29, pp. 17-25, 2002.

[2] J. L. Pelletier and S. S. Vel, "Multiobjective optimization of fiber reinforced composite laminates for strength, stiffness and minimal mass," Comput. Struct. , vol. 84, pp. 2065-2080, 2006.

[3] M. E. Fares, Y. G. Youssif, and M. A. Hafiz, "Multi-objective design and control optimization for minimum thermal post buckling dynamic response and maximum buckling temperature of composite laminates," Struct. Multidiscip. O., vol. 30, pp. 89-100, 2005.

[4] F. S. Almeida and A. M. Awruch, "Design optimization of composite laminated structures using genetic algorithms and finite element analysis," Compos. Struct., vol.88, pp.443-454

[5] K. Deb, S. Agrawal, A. Pratap, and T. Meyarivan, "A fast and elitist multi-objective genetic algorithm NSGA-II," IEEE T. Evolut. Comput., vol. 6(2), pp. 182-197, 2002.

[6] A. K. Kaw, Mechanics Of Composite Materials, CRC Press Taylor \& Francis Group, second edition, 2006

[7] R. Le Rich and J. Gaudin, "Design of dimensionally stable composites by evolutionary optimization," Compos. Struct, vol. 41, pp. 97-111, 1998.

[8] C. C. Chamis, "Simplified Composite Micromechanics Equations for Hygral, Thermal and Mechanical properties," SAMPE Quarterly, pp. 14-23, April 1984.

[9] M. Gen and R. Cheng, Genetic Algorithms and Engineering Optimization, John Wiley \& Sons, Inc, 2000

[10] K. Deb, Multi-objective Optimization using Evolutionary Algorithms, John Wiley and Sons, 2001.
[11] Genetic Algorithm and Direct Search Toolbox ${ }^{\mathrm{TM}}$ User's Guide 2004 2008 The MathWorks, Inc

[12] M. W. Hyer, Stress Analysis of Fiber Reinforced Composite Materials, McGraw-Hill, 1998. 